\section{AMERICAN ASSOCIATION FOR THE ADVANCEMENT OF SCIENCE.}

$A^{S}$ already notified, the forty-eighth meeting of the American Association for the Advancement of Science was held at Columbus, Ohio, on August 19-26. Dr. W. O. Thompson, President of the Ohio State University, welcomed the Association on behalf of the University, and Dr. Edward Orton, the President, in expressing the thanks of the Association, briefly referred to some of the scientific advances of the present century.

The address of Prof. F. W. Putnam, the retiring President of the Association, was printed in NATURE of September 7, and the following are extracts from some of the addresses delivered by the Presidents of the Sections.

The Fundamental Principles of Algebra.

In his address to the Section of Mathematics and Astronomy, Prof. Alexander Macfarlane reviewed historically and critically the several advances which have been made in the present cen tury respecting the fundamental principles of aigebra. The conclusion reached, after a statement and criticism of algebraic symbols, operations and laws, is as follows :-

If the elements of a sum or a product are independent of order, then the written order of the terms is indifferent, and the product of two such sums is the sum of the partial products; but when the elements of a sum or of a product have a real order, then the written order of the elements must be preserved, though the manner of their association may be indifferent, and a power of a binomial is then different from a product. This applies whether the sum or product occurs simply, or as the index of a base.

Descartes wedded algebra to geometry ; formalism tends to divorce them. The progress of mathematics within the century has been from formalism towards realism; and in the coming century, it may be predicted, symbolism will more and more give place to notation, conventions to principles, and loose extensions to rigorous generalisations.

The Field of Experimental Research.

Prof. Elihu Thomson described to the Section of Physics a few of the recent developments of physical science, and pointed out that physical research by experimental methods is both a broadening and a narrowing field. There are many gaps yet to be filled, data to be accumulated, measurements to be made with great precision, but the limits within which experimental work can be done are becoming, at the same time, more and more defined. In most fields of research progress in the future wil depend in an increasing degree upon the possession, by the in vestigator, of an appreciation of small details and magnitudes, together with a refined skill in manipulation or construction of apparatus. He must be ready to guide the trained mechanic, and be able himself to administer those finishing touches which often mark the difference between success and failure.

In conclusion, Prof. Thomson remarked that his endeavours had been to indicate in his address directions in which the field of experiment may be extended, and to emphasise the fact that research must be carried on by extension of limits, necessitating more liberal endowment of research laboratories. The physicist must avail himself of the powers and energies set in play in the larger industrial enterprises, and finally the field of possible exploration in physics by experimental methods has its natural boundaries, outside of which our advances in knowledge must be derived from a study of celestial bodies.

The riddle of gravitation is yet to be solved. This all-per. meating force must be connected with other forces and other properties of matter. It will be a delicate task, indeed, for the total attraction between very large masses closely adjacent, aside from the earth's attraction, is very small.

Scientific facts are of little value in themselves. Their significance is their bearing upon other facts, enabling us to generalise and so to discover principles, just as the accurate measurement of the position of a star may be without value in itself, but in relation to other similar measurements of other stars may become the means of discovering their proper motions. We refine our instruments; we render more trustworthy our means of observation; we extend our range of experimental inquiry, and thus lay the foundation for the future work, with the full knowledge that, although our researches cannot extend beyond certain limits, the field itself is, even within those limits, inexhaustible. No. I 560 , voL. 60$]$
The Definition of the Elemen't.

Prof. F. P. Venable briefly discussed the nature of the elements in his address to the Section of Chemistry. He passed in review some of the evidence which leads to the belief that the so.called elementary atoms are but compounds of an intimate peculiar nature, the dissociation of which has not yet been accomplished. Referring to the conclusions to which investigations lead, it was remarked that the hypothesis that the elements are built up of two or more common constituents has a larger number of supporters, and would seem more plausible than Graham's hypothesis. Some have supposed one such primal element by the condensation or polymerisation of which the others were formed. Others have adopted the supposition of two elements.

There are many practical difficulties in the way of these suppositions; the lack of uniformity in the differences between the atomic weights, the sudden change of electro-chemical character, and the impossibility, so far, of discovering any law underlying the gradation in the properties of the elements with the increase of atomic weights, are some of the difficulties. In comparing these two hypotheses, that of Graham seems very improbable. It is possible to think of valency as dependent upon the character of the motion of the atom, but one cannot well conceive of a similar dependence of atomic weight and all the other properties. There remains, then, the hypothesis of primal elements by the combination of which our elements have been formed. These molecules are probably distinguished from the ordinary mole. cules by the actual contact and absolute union of the component atoms without the intervention of ether.

Since these elemental molecules cannot as yet be divided, the name atom may be retained for them, but the idea of simplicity and homogeneity no longer belongs to them. The definition of an element as a body made up of similar atoms is equally lack. ing in fidelity to latest thought and belief, but chemists would scarcely consent to change it, and, indeed, it may well be retained, provided the modified meaning is given to the word atom. But, after all, an element is best defined by means of its properties. It is by close study of these that its elemental nature is decided, and through them it is tested. Complete reliance can no longer be placed upon the balance and the supposed atomic weight.

\section{The Devonian System of Canada.}

Mr. J. F. Whiteaves's address to the Section of Geology and Geography was upon the present state of knowledge of the Devonian rocks of Canada, from a palæontologist's point of view. In accordance with long usage in Canada, the line of demarcation between the Silurian and Devonian systems was drawn at the base of the Oriskany sandstone. The information that has so far been gained about the Devonian rocks of Canada was considered in geographical order, from east to west, under the three following heads, viz. (I) The Maritime Provinces and Quebec ; (2) Ontario and Keewatin; and (3) Manitoba and the North-west Territories.

The present state of our knowledge of the Devonian rocks of the whole Dominion, from a purely palæontological standpoint, was thus briefly summarised :-We now possess a fairly satis factory knowledge of the fossils of the Devonian rocks of Ontario, and of the relations which these rocks bear to the typical section in the State of New York. The fossil plants of the Gaspé sandstones have been described and figured by Sir William Dawson, and the remarkable assemblages of fossil fishes from the Upper Devonian of Scaumenac Bay and Lower Devonian near Campbellton have been worked out somewhat exhaustively, the earlier collections in Canada, and the later ones by the best ichthyological authorities in London and Edin. burgh. We have now some idea of the fossil fauna of the Manitoba Devonian, and have added materially to our know. ledge of the fossils of the Devonian rocks of the Athabasca and Mackenzie River districts. But, on the other hand, our knowledge of the organic remains of the Devonian of Nova Scotia is still in its infancy, and it would seem that the plant-bearing beds near St. John, N.B., which have so long been regarded as Devonian, may possibly be Carboniferous. In the Rocky Mountain region of Alberta we have not always succeeded in distinguishing Devonian rocks from Carboniferous, and we have yet to obtain a much fuller knowledge than we now possess of the Devonian fossils of Keewatin and the area to the south-west of James Bay. 


\section{ENGINEERING EDUCATION.}

The address of Prof. Storm Bull, before the Section of Mechanical Science and Engineering, was on engineering education as a preliminary training for scientific research work. The proposition put forward was that engineering education as furnished in the best technical schools of the world, together with the training obtained later in life as a practising engineer provides the best preliminary preparation for the successful prosecution of scientific research work.

\section{UNIVERSITY AND EDUCATIONAL INTELLIGENCE.}

Mr. A. G. Ashcroft has been appointed Assistant Professor of Engineering at the Central College of the City and Guilds of London Institute.

DURING the winter session I899-I900 at the University of Edinburgh, courses on practical experimental physiology, practical chemical physiology, and practical histology, will be given every week day, in addition to the usual five months' course on physiology.

AMONG the addresses to be delivered at the opening of the Medical Schools in the beginning of October are the following : -At the Middlesex Hospital the introductory address will be delivered by Mr. John Murray. At St. George's Hospital the introductory address will be given by Dr. Howship Dickinson. At University College the session will be opened by Dr. G. F. Blacker. At St. Mary's Hospital the address will be given by Mr. H. G. Plimmer. At Charing Cross Hospital the address will be delivered by Dr. Mitchell Bruce. At Guy's the term begins on October 2, when the first meeting of the session of the Physical Society will be held at 8 , in the new physiological theatre. Sir Samuel Wilks will preside. At the London School of Medicine for Women the introductory address will be given by the dean, Mrs. Garrett Anderson, after which the prizes for the past year will be distributed. The winter session of the London School of Tropical Medicine will open on October 2, when the new school will be formally opened to students. At St. Thomas's Hospital the session will open on October 3, when the prizes will be distributed by Prof. Clifford Allbutt. The winter session at Mason College, Birmingham, will begin on October 2, when Sir William Gairdner will deliver the introductory address. At University College of South Wales and Monmouthshire, Cardiff, the address will be given on October 6 by Prof. A. W. Hughes. At Yorkshire College, Leeds, the address will be given on October 2, and the prizes distributed by Dr. Byrom Bramwell. The session at University College, Liverpool, will begin on October 3 with an address by the Rev. S. A. Thompson-Yates, who will afterwards distribute the prizes. The introductory lecture at Queen's College, Manchester, will be given on October 2 by Sir J. Crichton Browne.

\section{SCIENTIFIC SERIAL.}

American Tournal of Science, September.-On the gas thermometer at high temperatures, by L. Holborn and A. L. Day. The authors seek for a type of gas pyrometer yielding the most trustworthy results, and eventually decide in favour of the iridio-platinum bulb as against porcelain. They fill the bulb with nitrogen, and use a saltpetre bath up to $750^{\circ}$, a zinc bath up to $900^{\circ}$, and electric heating for still higher temperatures, since flame gases pass bodily through the metal. - On the flicker photometer, by $\mathrm{O}$. N. Rood. The general idea of the photometer, which is independent of colour, is that the differently coloured beams of light traversing its axis should illuminate the two surfaces of a rectangular prism, facing the eye, and that by the oscillations of a cylindrical concave lens its illuminated surfaces should alternately and in rapid succession be presented to the eye. The resulting flicker vanishes when the two surfaces have the same luminosity.-A quantitative investigation of the coherer, by A. Trowbridge. The greater the charging potential of the coherer, the more rapid is the rise of the conductivity per unit increase in quantity of electricity discharged. Probably every coherer has a critical value of the difference of potential below which it will not act. In the ball coherer used this was 8 volts.-Double ammonium phosphates of beryllium, zinc, and cadmium in analysis, by Martha Austin. The preparation of these double ammonium phosphates is described in detail, and their utility in analytical processes is indicated.-An Albertitelike asphalt in the Choctaw Nation, Indian Territory, by J. A. Taff. The mineral, in both its physical and chemical properties, is shown to be an asphalt, and only differs from albertite in its solubility in turpentine. It occurs in veins from 4 to 25 feet thick.-A new meteorite from Murphy, Cherokee County, N.C. by H. L. Ward. The siderite described has a square fracture unusual in iron meteorites. - On the separation of alumina from molten magmas; and the formation of corundum, by J. $\mathrm{H}$. Pratt. The separation of alumina is well illustrated in nature in the occurrence of corundum, spinel, and chromite in the rocks of the peridotite group. Experiments in the laboratory show that the separation of alumina as corundum from molten magmas is dependent upon the composition of the chemical compounds that are the basis of the magma, upon the oxides that are dissolved with the alumina, and upon the amount of the alumina itself. When the magma is composed of a magnesium silicate without excess of magnesia, all the alumina held by such a magma will separate out as corundum.

\section{SOCIETIES AND ACADEMIES. \\ PARIS.}

Academy of Sciences, September I1.-M. Maurice Lévy in the chair.-On a new form of the equations of dynamics, by M. P. Appell. Some remarks on the new form of equation indicated in the Comptes rendus of August 7 and 28. The results obtained can be expressed in one theorem, with which is connected the principle of least constraint of Gauss. - The Perseids of $\mathrm{I} 899$, by M. G. Flammarion. The paper gives the results of the observations of MM. Antoniadi and Mathieu at the observatory of Juvisy on August II, 12 and I3. The results are given in tabular form, and the directions of the meteors observed are shown upon a map.-Remarks by M. Bouquet de la Grye on the above paper. It would be possible to utilise shooting stars as a means of determining differences of longitude between places unprovided with the telegraph. - On some geometrical relations between two systems of points defined by algebraic equations, by M. S. Mangeot.

\section{CONTENTS.}

Eclipses . . . . . . . . 489

A French Writer on Classification. By F. A. D. . 489

Our. Book Shelf :-

Reinke: "Die Welt als That."-E. A. M

Cauro: "La Liquéfaction des Gaz: Méthodes nouvelles-Applications" . . . . . . . 490

Letters to the Editor:-

Movement of Sea-Gulls with a Coming Change of Weather. - Lieut.-Colonel H. H. GodwinAusten, F.R.S.

Thermometric Scales for Meteorological Use.-H. Helm Clayton

The New Lunar Photographic Atlas.

The Dover Meeting of the British Association. By W. H. Pendlebury .

Section C.-Geology.-Opening Address by Sir Archibald Geikie, F.R.S., President of the Section

Section D.-Żoology.-Opening Address by Adam Sedgwick, F.R.S., President of the Section .

Our Astronomical Column:-

Holmes' Comet $1899 d$ (I892-III.)

Southern Variable Stars

The Bulletin de la Société Astr. de France

Solid Hydrogen. (Illustrated.) By Prof. James

Dewar, F.R.S. - ' ' ' id

American Association for the Advancement of

Science
University and Educational Intelligence . . . . . 515

Scientific Serial . . . . . . . . . . . . $5^{16}$

Societies and Academies . . . . . . . 516

No. I 560 , voL. 6o] 